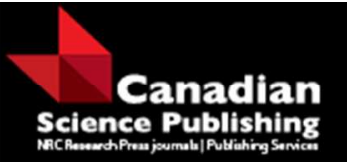

Canadian Journal of Forest Research

Revue canadienne de recherche forestière

\title{
Does information help forest owners form (better) timber price forecasts?
}

\begin{tabular}{|r|l|}
\hline Journal: & Canadian Journal of Forest Research \\
\hline Manuscript ID & cjfr-2015-0231.R1 \\
\hline Manuscript Type: & Article \\
\hline Date Submitted by the Author: & $19-$-Dec-2015 \\
\hline Complete List of Authors: & $\begin{array}{l}\text { Linden, Mikael; University of Eastern Finland, } \\
\text { Uusivuori, Jussi; Natural Resources Institute Finland (Luke), }\end{array}$ \\
\hline Keyword: & $\begin{array}{l}\text { non-industrial private forest owners, econometrics of complex survey } \\
\text { data,, forecasting, survey data, timber markets }\end{array}$ \\
\hline \multicolumn{2}{|l}{} \\
\hline
\end{tabular}

SCHOLARONE ${ }^{\mathrm{m}}$

Manuscripts 
1 Does information help forest owners form (better) timber

2 price forecasts?

3

4

$5 \quad$ Mikael Linden

6 University of Eastern Finland

$7 \quad$ Yliopistokatu 2, P.O. Box 111

$8 \quad$ FI-80101 Joensuu, Finland

9 mika.linden@uef.fi

10

11 Jussi Uusivuori*

12 Natural Resources Institute Finland (Luke)

13 Viikinkaari 4

14 FI-00790 Helsinki, Finland

$15+358295326000$

16 jussi.uusivuori@luke.fi

17

$18 *$ Corresponding author 
1 Abstract: Impacts of forestry related information on forest owners' ability to forecast timber

2 price changes are studied. Large survey data on non-industrial private forest owners are

3 explored with methodology on discrete and limited dependent variable econometrics. We find

4 that forest owners who regard information sources as important for themselves, and who are

5 active users of information sources are better prepared to provide a timber price forecast as

6 compared to forest owners without these attributes. This tendency is not as clear among forest

7 owners who have contacts with forestry professionals more than other forest owners.

8 Availability and use of information did not seem to improve forest owners' forecasting

9 accuracy, however. Within market conditions in which timber prices fell quite sharply,

10 information led forest owners to predict no change in timber prices.

11

12 Key words: non-industrial private forest owners, econometrics of complex survey data, 13 forecasting 


\section{Introduction}

Besides information on best forest management practices, information on timber

3 prices and market conditions are important to forest owners. Landowners' plans to harvest

4 and sell timber are affected by their forecasts on market prices. Therefore also sufficient

5 information on prices and markets may be needed for a smooth functioning of timber

6 markets.

7 The question of whether information helps forecasting timber prices has been studied in

8 previous literature from the point of view of market efficiency. Typically if agents on the

9 timber markets take into account all available information, the market is said to be

10 informationally efficient and the price determination will give rise to non-stationary, first-

11 order integrated, time series of timber prices (Washburn and Binkley 1990). In this case the

12 prices follow a random walk type behaviour without having memory properties that could be

13 used for forecasting. In contrast, if timber price process is stationary and mean reverting (see

14 e.g., Brazee and Mendelsohn 1988; Davis and Cairns 2012), then analysis can be used to

15 predict next period's prices (Anderson et al. 2013).

16 A related question is how and to what extent forest owners actually take advantage of

17 available information when forming timber price forecasts, and whether this information

18 helps them do better forecasts. While studies exist on timber harvesting and investment

19 effects of public programs related to forestry aid, subsidies, monitoring, forest plans and

20 general guidance (Boyd 1984, Royer 1987, Hyberg and Holthauser 1989, Löyland et al. 1995,

21 Zhang and Flick 2001, Beach et al. 2005), there is no (as known to us) literature dealing with

22 how public information affects timber price forecasts. A natural reason for the missing

23 analysis has been the non-existence of individual level data on price expectations. In this

24 study we overcome this limitation by using a large Finnish survey data set on non-industrial

25 private forest owners revealing survey participants' timber price expectations. 
Following the chosen line of approach, rather than looking at the longitudinal

2 properties of timber price series and linking this to the usefulness of price information, we

3 investigate the question of how access to information and experienced importance of the

4 information among private forest owners affects their timber price forecasting performance.

5 With a data set which is short in longitudinal direction - we only have one year's forecasting

6 outcomes - but wide in the direction of individual forecasts - forecasts by 6500 forest owners

7 - we explore both the forecasting process formation and forecasting accuracy of the forest

8 owners. With this data set we are able to combine group-wise variables measuring several

9 dimensions of how accessible information is to an individual forest owner and to what extent

10 it is used. To distinguish the impact of information variables from owner-wise background

11 and other variables we control for the background variables, as well as for a number of

12 activity variables measuring e.g. recent activity on timber markets and in forest management.

13 Consequently, we contribute to the literature by providing empirical measures for the

14 net impacts of various information sources on how easily forest owners do form forecasts on

15 one hand, and how accurate their price forecasts are on the other hand. We do this by

16 utilizing methodology on discrete and limited dependent variable econometrics designed for

17 complex survey data. We also study the problem of non-response and missing observations in

18 detail with selected multinomial choice and data imputations methods.

19 The question of forecasting efficiency has been investigated with data from energy

20 markets. Auffhammer (2007) studied the rationality of published EIA forecasts under

21 symmetric and asymmetric loss. Sakva (2005) evaluated the accuracy of annual energy

22 outlook reports from 1982 to 2003 by error decomposition and regression. Neill and Desai

23 (2005) assessed and analyzed the accuracy of projections of US energy consumption

24 produced by EIA over the period 1982-2000. 
1

In the current study, our methodological approach comes somewhat close to methods used in economic gaming literature (e.g. odds on horse races) where game (race) outcome categories are known with estimated frequencies on previous game results. In that literature, the predictions of multinomial outcomes are derived with individual player level characteristics and information to test the rationality of race outcome forcasts (Jullien and Salanie 2000, Bolton and Chapman 1986, Sung and Johnson 2008). Our data on timber price expectations also consist of wide multinomial dimension which we link with large set of data on information, economic activity and landowner background variables.

This type of analysis is emphasized by the econometric forecasting literature wherein the information and forecasting heterogeneity is analysed with forecast densities, loss functions, and advanced survey sampling methods (see Pesaran and Skouras 2002, Pesaran and Weale 2006).

\section{Material and Methods}

\section{Sampling design and price change expectations}

Forest owners' price change expectations were inquired as part of a bigger survey questionnaire in 2008-09. The final survey sample size was 12,848 forest owners. The survey considered solely-owned, family-owned and jointly owned non-industrial forest holdings in Finland, with a minimum size of 5 hectares. Some 6,318 owners returned acceptable answers to the questionnaire.

The survey answers were given during January through March in 2009. The owners were inquired about their timber price expectation of the change of prices at the end of the year 2009 in relation to the price level at the beginning of the year 2009. In Finland, some 740000 non-industrial forest owners (incl. joint owners) own about 60 percent of the forestland. Most of the forest properties are small in size, forest lots larger than 100 ha 
1 account for only 5 percent of the total number of forest properties. The most typical way of

2 selling timber is on stumpage. In the current sample, some 40 percent of the respondents

3 lived in the near vicinity of their forest property (Hänninen et al. 2011).

4

5

6

We aggregated the data into the following compromise variable named CHOSEN that describes the following price change categories from which the forest owner had to choose one:

$$
\begin{aligned}
& 5=\text { an increase of prices of at least } 11 \% \\
& 4=\text { price changes within the margin of } 5 \% \text { to } 10 \% \\
& 3=\text { price changes within the margin of }-4 \% \text { to } 4 \% \\
& 2=\text { price changes within the margin of }-5 \% \text { to }-10 \% \\
& 1=\text { a decrease of prices of }-11 \% \text { or more } \\
& 0=\text { don't know }
\end{aligned}
$$

The distribution of answers exhibits a positive skewness with mean of 1.85 and median of 2.00. Thus, on average the forest owners expected timber prices to decrease. $41.2 \%$ of the primary survey units - the forest owners - returned acceptable answers to the questionnaire. As the questions were sent to every 24th forest owner in a random sample of 1000 forest owners in each Forest Center, the survey fulfills the requirement of random sampling (without replacement) at the sub-sample level.

The problem of non-response is difficult to handle without information on the nonrespondent survey units. An interview indicated that the share of farmers was slightly bigger among the non-respondents compared to the respondents. We proceed with the assumption that non-response units do not differ systematically from the ones that gave acceptable answers. However, we do estimate the extent of the non-response bias effect on our population estimates by missing value analysis and data imputation methods, as explained later.

We argue that the missing values in the sample can also reveal something about the possible non-response bias. There were 676 missing values $-10.7 \%$ of the total number of 
1 acceptable answers - on the price change variable CHOSEN. Missing values on other

2 variables were also present, so that a total of 1840 list-wise observation values for all

3 variables remained. Typically missing values are related to the non-response since forest

4 owners who give many empty or "I don't know" answers are likely to be more similar to

5 those owners who do not respond to the survey at all (non-response) as compared to those

6 who give complete answers in the survey. Thus, if we are able to show that missing values in

7 the analysed sample do not affect the estimation results, then the non-response bias in these

8 estimates may not be severe.

9 The effects of non-response are analyzed in the following in the context of how 10 information on forestry and timber markets affects forest owners' choice of the different 11 alternatives concerning the price change expectations. The argument that non-respondents 12 (and forest owners who provide missing values to the survey questions) are the less informed 13 is important in this context. Forest owners who are not actively following timber market 14 developments may more likely fall into the category of non-respondents in the large and time consuming survey. In this sense our results may overstate the importance of information on timber price expectation formation. To compensate for this we retain in the analysis the 17 choices on the alternative "I don't know". This protects us in part from the non-response bias, assuming that survey units with this answer are more like non-respondents and missing value 19 providers as compared to survey units who did provide price change answers. Finally, the estimation with the imputed missing values gives us an additional measure of the nonresponse bias to be used in the analysis.

The sample proportions of answers to price change alternatives are unbiased estimates

23 of population proportions under the assumption that non-response is not systematic. Table 1

24 gives the $95 \%$ confidence intervals (CI) for the population shares of the answer categories.

25 Coefficient of variation $(\mathrm{CV})$ measures the precision of the estimates in $\%$-values. As can be 
1 seen from the table, the population proportion estimates are quite precise. This means that the

2 corresponding share observation numbers give a solid starting point to the multinomial and

3 ordered response analysis of heterogeneous price change expectations, which we will proceed

4 later. It is well-known that stratification decreases sampling variance while clustering has the

5 opposite effect (Heeringa et al. 2010, Raj 1968). In our case, when the variances of the

6 population share estimates for price change alternatives were corrected with the observed

7 strata they in fact became considerably smaller. These sample design corrections are also

8 made in the multinomial regression estimations.

\section{Table 1.}

\section{Variables}

12 From the close to 70 survey variables we chose the ones that we considered to be the most relevant for price expectation formation in addition to the ones describing the respondents' socio-economic background. We categorize the sample variables into three groups to make

the analysis more tractable and efficient. Information variables reflect the importance of various information sources available for a forest owner concerning the relevant market conditions in forming price expectations (Table 2).

Table 2.

The summary statistics of the information variables are listed in Table 3.

\section{Table 3.}

21 Activity variables describe activities and decisions that assist the forest owner to improve his/ 22 her knowledge of forestry and market conditions (for more details, see Table A1-1 in 23 Appendix 1). These variables are not fully fixed to the forest owner (unlike age or gender). 24 Background and non-activity variables variables reflect forest owners' socio-economic 
1 background. In most of the cases, the values of these variables are fixed for an individual

2 forest owner (Table A1-2 in Appendix 1).

\section{Methods}

4

5

We focus on three related methods to study the questions of which variables make the forest owner to choose one of the price change alternatives instead of not answering at all, and which variables are connected to smaller biasedness in terms of forecast errors. First we use multinomial logit $(M N)$ approach relying on the IIA -assumption that the choices are based only on pair-wise comparison. $M N$ pays no attention to the fact that the choice alternatives are ordered. Ordered (multinomial) logit model $(O L)$ takes this feature into account. However, with $O L$ one should not use the answers in the "I don't know" category. To overcome this and the IIA problem we extend our analysis with the nested (multinomial) logit approach $(N L) . \quad N L$ model is based on the assumption that a forest owner first decides between the "I don't know" alternative and the other alternatives. In the second stage, if he/she decided not to give the "I don't know" answer, he/she chooses one of the ordered price change alternatives. The model treats the "I don't know" answers (non-participation) as a separate process with its own covariates from the part of the model (participation) that focuses on the given numeric alternatives of price changes. However during the estimation and testing phase of $N L$ model the results indicated that this model alternative does not provide any new results or insights compared to the $M N$-approach (e.g. it did not reject the IIA assumption). Thus in what follows, we focus only on $M N$ and $O L$ approaches.

\section{Multinomial logit, $M N$}

Multinomial variables are characterized by mutually exclusive and exhaustive non-ordered categories. If there are $J+1$ unordered outcomes of the dependent variable $y_{i}$ then assigning the values $0,1,2, \ldots, J$ to the outcomes leads to the probability presentation 
1

1) $\quad P\left(y_{i}=j \mid \boldsymbol{x}_{i}\right)=\pi_{i j}=\frac{\exp \left(\boldsymbol{x}_{i}^{\prime} \boldsymbol{\beta}_{j}\right)}{\sum_{r=0}^{J} \exp \left(\boldsymbol{x}_{r}^{\prime} \boldsymbol{\beta}_{r}\right)}, j=0,1,2, \ldots, J$.

2 Note that this $M N$ model has $(k+1) \times J$ different parameters when each parameter vector $\boldsymbol{\beta}_{r}$

3 has $k+1$ elements. However the probability levels $\pi_{i j}$ are themselves unidentified since any

4 constant can be added to each of the $\boldsymbol{\beta}_{r}$ 's without affecting their difference. Thus typically

5 one of the alternatives $j \in J+1$ is chosen as base category or baseline where we set $\boldsymbol{\beta}_{j}=\boldsymbol{0}$,

6 which provides the reference point for all other alternatives.

7

8 It is important to keep in mind which category is the base category. All estimated coefficients

9 in the vector $\boldsymbol{\beta}_{r}$ need to be interpreted relative to this base category. If the model is correctly specified, the maximum likelihood (ML) estimator is consistent, efficient, and asymptotically normal (Greene 2012, Chapter 18). A consistent estimator of the covariance matrix of parameter estimates can be obtained by inverting the Hessian evaluated at the ML estimates. The interpretation of the estimates $\boldsymbol{\beta}_{r}$ needs special attention. We are interested in the discrete and the marginal changes of probabilities in response to a (unit) change in the explanatory variables. For a discrete variable $x_{i l}-$ such as a 1/0 -dummy variable - we have

$$
\Delta \pi_{i j}=-\sum_{j=1}^{J} \Delta \pi_{i j}=P\left(y_{i}=j \mid x_{i}+\Delta x_{i l}\right)-P\left(y_{i}=j \mid x_{i}\right)
$$

2)

$$
=\frac{\exp \left(\boldsymbol{x}_{i}^{\prime} \boldsymbol{\beta}_{j}+\beta_{l}\right)}{1+\sum_{r=1}^{J} \exp \left(\boldsymbol{x}_{i}^{\prime} \boldsymbol{\beta}_{r}+\beta_{r}\right)}-\frac{\exp \left(\boldsymbol{x}_{i}^{\prime} \boldsymbol{\beta}_{j}\right)}{1+\sum_{r=1}^{J} \exp \left(\boldsymbol{x}_{i}^{\prime} \boldsymbol{\beta}_{r}\right)}, j=1,2,3, \ldots, J
$$

The interpretation of the above is the following: given a ceteris paribus change $\Delta x_{i l}=1$, the probability of observing outcome $j$ changes by $\Delta \pi_{i j}$. Note that the exact amount of the change depends on the specified values to which we fix the regressors. 
2 effects $(M P E)$ when the base category is the first category

3

3)

$$
M P E_{i 0 l}=\frac{\partial x_{i 0}}{\partial x_{i l}}=-\pi_{i l} \sum_{r=1}^{J} \pi_{i r} \beta_{r l}
$$

$$
M P E_{i j l}=\frac{\partial x_{i j}}{\partial x_{i l}}=\pi_{i l}\left[\beta_{j l}-\sum_{r=1}^{J} \pi_{i r} \beta_{r l}\right], \quad j=1,2,3, \ldots, J
$$

4 We recognize that the MPE of one outcome depends on the probabilities (as well as on the 5 parameters and regressors) of all other outcomes. Thus we could compute for each sample

6 unit $i$ the discrete probability responses and MPE's but typically we need some sample mean

7 estimates. The average marginal probability effects are

8

$$
A M P E_{i l}=\frac{1}{n} \sum_{i=1}^{n} M P E_{i j l}, \quad j=1,2, \ldots, J
$$

9 Alternatively we could compute the discrete and marginal effects at the sample mean values of regressors $\left(\bar{x}_{1}, \ldots, \bar{x}_{k}\right)$ producing MPE's at the means (MAPE). Note also that we have to use Delta method to calculate the standard errors of these estimates.

\section{Ordered logit, $O L$}

In the context of choice between alternative price change expectations the $M N$ approach misses some relevant information. We can argue that the ordering or the ranking of the alternatives is important in here, i.e. that it means something different to a forest owner to choose among - although classified - numerical values of price changes as compared to choosing e.g. between a blue and a red car. There is an obvious order in the answer categories from the lowest price change expectation to the highest. Models for multinomial data are still feasible but inefficient since they ignore the ordering information.

The $O L$ model is most easily motivated with latent variable approach. We cannot see the true (latent) continuous variable $y_{i}^{*}=\boldsymbol{x}_{i} \boldsymbol{\beta}+\varepsilon_{i}$ that determines the sample unit's choices 
1 among the alternatives. Instead we observe the discrete values of $y_{i}=j$ with values $2 j=0,2, \ldots ., J$, i.e. the preferred choices by the survey units. Thus, we need a mechanism that

3 links $y_{i}^{*}$ 's with $y_{i}$ 's. We assume that observations are related to $y_{i}^{*}$ 's in the following way

4

$$
\begin{aligned}
& y_{i}=0 \text { if } y_{i}^{*} \leq 0, \\
& y_{i}=1 \text { if } 0<y_{i}^{*} \leq \mu_{1}, \\
& y_{i}=2 \text { if } \mu_{1}<y_{i}^{*} \leq \mu_{2}, \\
& y_{i}=J \text { if } \mu_{J-1}<y_{i}^{*} \leq \mu_{J} .
\end{aligned}
$$

5 Above, the $\mu_{j}$ 's are unknown parameters to be estimated along with the $\boldsymbol{\beta}$, although we

6 know the true margins restricting the choice alternatives. In this context we use the standard

$7 O L$ and compare the estimated $\mu_{j}$ 's to the observed margins. This strategy enables us to pay

8 attention to forest owners' unobserved selection rules, compared to the given ones. In

9 principle the respondents could respond to the questionnaire with their own $y_{i}^{*}$ if asked to do

so. However, given only five possible alternatives to answer, they choose the one that most closely represents their own valuation or intensity on the question (Greene, 2012).

Once the distribution function of $F(\varepsilon)$ has been specified, the probability of a particular outcome is determined by the area under the density function between relevant thresholds $\mu$. The $O L$ model is based on the assumption that $F(\varepsilon)$ is logistic, and the probabilities are given by

$$
\pi_{i j}=F\left(\mu_{j}-\boldsymbol{x}_{i}^{\prime} \boldsymbol{\beta}\right)-F\left(\mu_{j-1}-\boldsymbol{x}_{i}^{\prime} \boldsymbol{\beta}\right), \quad j=0,1,2, \ldots, J .
$$

17 The ML estimation yields consistent, asymptotically efficient, and asymptotically normally 18 distributed estimators. The parameter estimates themselves are not of much interest, since they lack a direct interpretation. Of interest are the marginal probability effect $(M P E)$ of the $l$ element in $\boldsymbol{x}_{i}$ on probabilities of different ordered choices $j=0,1,2, \ldots, J$ : 
1

$$
M P E_{i j l}=\frac{\partial \pi_{i j}}{\partial x_{i j l}}=\left[f\left(\mu_{j-1}-\boldsymbol{x}_{i}^{\prime} \boldsymbol{\beta}\right)-f\left(\mu_{j}-\boldsymbol{x}_{i}^{\prime} \boldsymbol{\beta}\right)\right] \beta_{l},
$$

where $f(z)=d F(z) / d z$ is the density function. $A M P E$ 's and MAPE's are calculated similarly

3 as in $M N$ case. Note that MPE can be used to approximate the discrete change in a probability

$4 \quad$ with $\Delta \pi_{i j} \approx M P E_{i j l} \Delta x_{i l}$.

\section{Missing value analysis and data imputation}

6 Missing value analysis helps address several concerns caused by incomplete data (Carpenter 7 and Kenward 2013, Allison 2002). If cases with missing values are systematically different 8 from cases without missing values, the estimation results can be misleading. Also, missing 9 data may reduce the precision of calculated statistics because there is less information than originally planned. The data on $Y$ are said to be missing completely at random $(M C A R)$ if the probability of missing data on $Y$ is unrelated to the value of $Y$ itself or to the values of any other variables in the data set. This means that data - including missing data values - are a random sample of population and the sample estimation results are valid. MCAR condition is demanding for non-experimental data. It is quite often rejected as we can observe and test that missing values of $Y$ are related differently to corresponding observed values of $X$ variables compared to the observed values of $Y$ and $X$. A weaker condition for proper analysis of non-experimental data is therefore useful. Data on $Y$ are said to be missing at random $(M A R)$ if the probability of missing data on $Y$ is unrelated to the value of $Y$, after controlling for other variables $X$ in the analysis. In practice we test for MCAR assumption first, and if it is rejected we proceed to different methods to estimate and forecast missing values when the data are $M A R$. The most efficient and consistent approaches are the $E M$-algorithm and multiple imputation methods (MI's).

Many variants of the MI method are available with different features suited for different data sets and models, but the underlying idea is similar. Generally, imputation is a 
1 process of estimating or predicting the missing observations. The goal is to minimize

2 approximation errors introduced by the imputation.

3 If the problem are the missing values of the dependent variable $y_{i}$ with MAR and the

4 missing data mechanism is independent of the model for $y_{i}$, the $M I$ set-up is quite simple. It is

5 a mixture of bayesian and bootstrap or MCMC simulation methods (see Greene 2012,

6 Chapter 4.7.4, and Cameron and Trivedi 2005, Chapter 27).

\section{Results}

\section{$8 \quad$ Missing value analysis}

9 Table A2-1 in Appendix 2 gives the missing value statistics of the continuous variables in our sample. We observe that the share of missing values does not exceed $13 \%$ for any variable. However, if we deleted missing values on the list-wise method for all variables our sample would reduce to 3187 observations. This would have major effects e.g. on the regression results of the dependent variable CHOSEN. The table also shows that some variables are quite non-normally distributed.

Table A2-2 presents the effects of missing values of the dependent variable CHOSEN on the values of other variables. For example, the mean of the variable INFO values with missing values on CHOSEN is 6.56 and with observed CHOSEN it is 9.09. That the variance between the present and missing value categories is equal is rejected for all variables except ACTIVITY_A with the t-test. This means that the $M C A R$ condition is rejected as the values of variables are clearly related to the probability of missing values of the variable CHOSEN. A more formal test (Little's $M C A R$-test) also rejects $M C A R$ with p-value of 0.00 . report only the results for those variables that exhibit significant difference with the number of missing values of the variable CHOSEN. 
The MCAR condition is rejected for the data. Therefore, the regression analysis of the

2 variables determining the observed outcome values of the variable CHOSEN must be

3 augmented with imputation methods that take into account missing values. Then, if the

4 results extended with the imputation data do not conflict with the observed data results we

5 can claim to have succeeded, at least to some extent, to avoid the missing value and non-

6 response problems.

\section{Small model results: Information variables as sole explanatories}

Table 4 reports the $A M P E$ 's and their $z$-values of the small model including only the continuous information variables (see Table 3 above). The full $M N$ and $O L$ estimation results are available from the authors. For the derivation of the standard errors of the parameter estimates in the models with complex survey data see Heeringa et al. 2010 (Chapters 8 and 9).

We observe from Table 4 that increased magnitude of information decreases the average marginal probability to choose the alternative 0 , i.e. the "I don't know" alternative. The implication is that forestry information does affect forest owners' forecast formation as it helps them to avoid the "I don't know" answers and the non-response. The activity level of reading forestry journals seems to have the strongest impact on choosing an estimate for timber price development. However, personal contacts with forestry professionals have a weaker impact on the probability of not choosing the "I don't know" category. For the other categories of the variable CHOSEN the significant AMPE's are positive. Thus, more information provision leads to increased probability of choosing one of the numeric alternatives of price changes. The probability effects seem to be largest in categories 2 and 3 where prices are expected to decrease somewhat or remain the same. For the variables INFO (measuring the sum of personal valuations of the importance of various information sources) and JOUR (measuring the importance of forestry journals as information source) it is the 
1 neutral price forecast category 3 that receives the highest probability estimates. The results

2 with ordered logit $(O L)$ model are close to the multinomial logit $(M N)$ results but some

3 differences exist. For the category 1 the marginal probability effects of the information

4 variables are negative. Thus, according to the OL model results, increased information

$5 \quad$ reduces the probability of choosing alternatives 0 or 1 .

\section{Table 4.}

7 Large model results: controlling for the effects of the background and activity variables

8 In the larger model, in addition to the information variables, we also used the activity and

9 the background variables to explain the probability of providing a timber price forecast (see

10 Appendix 2). Using all the sample variables led to missing value and multicollinearity

11 problems. After testing with different variable combinations the selection of explanatory

12 variables shown in Tables 5 and 6 led to appropriate estimations for the $M N$ and $O L$ choice

13 models. Table 5 reports the $M N$ results for $A M P E$ 's. (The full estimation results are available

14 from the authors.)

Table 5.

After controlling for the background and activity variables, the impact of the information variables on selecting among the price forecast alternatives was maintained: the general importance of various information sources as well as the activity of reading forestry journals helped forest owners avoid the "I don't know" alternative. However, the contacts by forestry professionals lost its significant impact after controlling for the background 21 variables.

22 Surprisingly, the only variable among the background and activity variables that has statistical significance in all of the price change alternatives is the VALUE_estim -variable measuring the forest owner's stated monetary compensation level for which he/she would be 
1 ready to sell his/her entire forest property. In categories 0 and 5 this variable has a negative

2 effect on the marginal probability of choosing corresponding alternatives. For the other

3 alternatives the effect is positive. We can argue that a forest owner who values forest assets

4 highly, is also well informed about the current market timber prices or involved trend in

5 prices that are relevant for deriving price change expectations and forecasts. The related 1/0

6 -variables on timber selling during the years 2003-2008 and plans on selling in years 2009-

72013 (SELLINGS, SELLINGS_exp1, SELLINGS_exp2, SELLINGS_exp3) have varying

8 impacts on the price change alternatives. Still the probability effects on the "I don't know"

9 alternative are negative. Thus forest owners who have some timber selling experience or

10 plans to sell have higher probability to choose price change categories than do forest owners

11 who have no recent timber selling experience or plans. Similar effects seem to have the

12 variable that relates the forest owner to have employment in the forest sector (OCC_st3,

13 FOREST_job2), the variable indicating that the forest land has been acquired through market

14 purchase (DELIV_m), and the variable indicating some degree of professional education

15 (EDU_1, EDU_2). In contrast, female, Swedish speaking, and non-active forest owners

16 choose the "I don't know" with higher probability than do male, Finnish speaking, or active

17 forest owners.

18 Table 6 lists the $O L$ estimation results. The information variables INFO and JOUR have 19 negative probability effects in price change categories 0 and 1 but in other categories their 20 effects are positive. These variables receive the highest probability effects in the neutral price 21 forecast category 3 (timber prices remain the same or they either increase or decrease 22 somewhat), as was the case in the $M N$ estimation as well. Activity variables related to timber 23 market operations are significant both in the statistical and economic terms in all categories.

24 Contrary to this, having regular housing on the forest holding (PERM_h), having plans of 25 buying, selling, or releasing forest land in the years 2009 - 2013 (HOLDING_dec) seem not 
1 to decrease the probability of choosing "I don't know" alternative. However self-employment

2 in forest sector (OCC_st3) and having a forest plan (FOREST_plan) help to choose among

3 the numeric price alternatives.

4

5

6

\section{Table 6.}

The background variables HOLDING_size, LANGAUGE, GENDER, non CONTACT and non_ACTIVITY have a probability increasing effect on giving the "I don't know" answer. Thus if the forest property is large, the owner is female and Swedish speaking and has not had contacts with forestry professionals or has not participated forestry information meetings, then the answer is more likely to be the "I don't know" category than the other categories. In general the $O L$ results are in line with and confirm the earlier $M N$ estimation results.

Note that complex survey sample setting does not allow for calculating McFadden's pseudo- $R^{2}$-values as an estimate of model fit. When estimating the models in simple random sample setting $(S R S)$ pseudo- $R^{2}$-values were between 0.027 and 0.086 .

\section{Results with imputed data}

The missing value analysis indicated that missing values have an impact on the observed values in in our sample. Next we used the multiple imputation (MI) methods to reestimate the small $O L$ model and to check whether the missing values of the variables CHOSEN, INFO, JOUR and CONTACT_A have led to a bias in the results obtained above (for details of MI-methods, see Carpenter and Kenward 2013.

The results (obtainable from the authors) indicated that both the parameter estimates and the AMPE's are close to the results obtained above when discarding the missing observations. Even if larger in absolute terms, in all of the cases - except the $A M P E$ values for the category 2 - the $95 \%$ CI's contained the corresponding earlier estimates obtained 
1 with missing values. The corresponding results were also obtained for the large $O L$ model

2 and with the $M N$ model. In general, the $M I$ results indicate that the estimation results obtained

3 with discarding missing values are reliable.

\section{$4 \quad$ Does information help derive more accurate price change forecasts?}

5 Next we analyze the predictions of the multinomial model results using price category values

6 of actual price change values, as observed at the end of the year 2009. Regional level price

7 data are used. The timber price variable was calculated in the following way. Weighted

8 average of price changes (i.e. differenced log prices) from January, February and March to

9 December 2009 were derived in each price region. The weights on prices were the quantity

10 observations of the total sold volume $\left(1000 \mathrm{~m}^{3}\right)$ of timber in a region on the timber

11 assortments (spruce, pine, birch) separated with pulp and log wood. Finally the mean of three

12 period specific weighted price changes were calculated in each region. Table 7 shows the

13 actual price changes at the end of year 2009 and the corresponding survey price change

14 categories (see Data section above) for the country level and in six price regions.

\section{Table 7.}

We observed from the multinomial and ordered logit model results that the positive marginal probability effects of the information variables are largest in the price change categories 2, 3 and 4 within which prices are expected to decrease somewhat, remain the same or increase somewhat, respectively. The results also showed that alternative 1 (a decrease of prices by $-11 \%$ or more) was not well explained by the models. In fact, the $O L$ results even indicated that the probability effects of the information variables were negative

22 for this alternative. This result is particularly important, since alternative 1 is the one where 23 the expectations turned out to be the least biased (i.e. have smallest forecast errors).

24 Therefore, the implication is that it is possible that increased information (as measured by the 
1 INFO and JOUR variables) may actually have caused the forest owners to avoid the correct

2 timber price forecast categories.

3 The above result is surprising since we have above shown that information variables have a

4 definite positive predictive power in the formation of price change expectations. However, if

5 the price change expectations are biased from the beginning (less than $40 \%$ expectations were

6 in alternative categories 1 and 2) and the model predictions do not support these categories,

7 then we can ask the value of information in expectations formation. The somewhat bipolar

8 conclusion is that while the market and other information assist forest owners in forming

9 price forecasts, this information at the same time supports forest owners in forming too 10 optimistic and thus biased forecasts.

\section{Discussion and conclusions}

13 We used a large and complex survey data to study nonindustrial private forest owners' timber price forecast formation and accuracy as explained by variables linked to

15 forestry related information and owners' background. As the data were highly group-wise 16 discrete we used multiple discrete variable techniques in estimating the parameters and 17 marginal probabilities. Similarly, the data required a detailed missing value analysis.

18 Three main outcomes can be summarized based on obtained results. First, information helped 19 forest owners form timber price forecasts. Second and third, while information seemed to make forest owners lean toward choosing the most neutral timber price forecast, it made them not to choose the most accurate price forecast. These outcomes were upheld in estimations with and without controlling for the background variables describing the forest owners and 23 their decision-making context.

24 The first outcome is naturally a positive result from the point of view of policies and public programs aiming at increased use of market and forest related information by nonindustrial 
1 private forest owners. On the other hand, the second and third outcomes are indeed

2 problematic from the same point of view. It has to be kept in mind, however, that we had

3 only one time period from which the forecast accuracy was measured. In this case

4 information led the survey respondents choose too optimistic (from landowners' point of

5 view) timber price estimate as the realized prices fell fairly substantially. Note, however, that

6 at the time period of the survey, timber prices were fluctuating quite strongly. Therefore, our

7 results do not reveal what the relationship between information and timber forecast accuracy

8 would have been in different market and price development conditions. For example, while

9 our results indicate that information did not help forest owners foreseeing a downward shift

10 in timber prices, it is possible that it would still have helped them foresee a neutral or upward

11 price development, had one of those been the case.

12 We should also keep in mind the nature of the information variables used in the study. The 13 main outcomes were linked to two types of variables. First, a composite variable measured 14 the experienced importance of different forestry information sources. Second, a variable 15 measuring the use of forestry journals and other media, obtained parameter values indicating 16 that those factors did help forest owners form timber price change forecasts. In contrast, a 17 third type of information source, measured by forest owners' exposure to personal 18 professional contacts did not seem to have a significant effect on forest owners' ability or 19 willingness to form timber price forecasts, when controlling for background variables. One 20 can ask whether the professional contacts focus on other issues than timber market and price 21 development, and whether this leads to a shift in the forest owners' attention away from 22 following timber price development. Of the variables related to owners' background features, 23 we found out that the higher a forest owner's monetary appreciation of the forest property 24 was, the easier it was for him/her to form a timber price forecast. A high valuation of the 25 property thus seems to lead into higher ability/willingness to forecast timber prices. 
In summary, the results suggest that forestry related information supported forest owners in forming biased, too optimistic timber price forecasts in Finland and during the time period examined. This is an important result, and it would be interesting to see if it holds with comparable data sets representing other regional or market development contexts.

\section{References}

Allison, P.D. 2002. Missing Data. Sage, Thousand Oaks.

Andersson, L., L. Hultkrantz , and P. Mantalos. 2013. Stumpage Prices in Sweden 19092011: Testing for Non-Stationarity. Working Papers 2013:1, Örebro University, School of Business.

Auffhammer, M. 2007. The rationality of EIA forecasts under symmetric and asymmetric loss. Resource and Energy Econmics 29(2):102-121.

Beach, R.H., S.K. Pattanayak, J.-C.Yang, B.C. Murray, and R.C. Abt. 2005. Econometric studies of non-industrial private forest management a review and synthesis. Forest Policy and Economics 7: 261-281.

Bolton, R.N. and R.G. Chapman. 1986. Searching for positive returns at the track: a multinomial logit model for handicapping horse races. Management Science 32(8): 1040-1060.

Boyd, R. 1984. Government support of non-industrial production: the case of private forest. Southern Economic Journal 51(1): 89-107.

Brazee, R.J., and R. Mendelsohn 1988. Timber harvesting with fluctuating prices. For.Sci. 34(2):359-372.

Cameron, A.C. and P.K. Trivedi. 2005. Microeconometrics: Methods and Applications. CUP. Cambridge.

Carpenter, J.R. and M.G. Kenward. 2013. Multiple Imputation and its Application. Wiley, NY.

Davis, G.A. and R.D. Cairns. 2012. Good Timing: The Economics of Optimal Stopping. Journal of Economic Dynamics and Control 36: 255-65.

Greene, W.H. 2012. Econometric Analysis, 7th ed. Pearson. Harlow.

Heeringa, S.G., B.T. West, and P.A. Berglung. 2010. Applied Survey Data Analysis. CRC Press, Boca Raton. 
1 Hyberg, B. and D. Holthausen. 1989. The behavior of non-industrial private forest

Hänninen, H., Karppinen, H. and Leppänen, J. 2011. Suomalainen metsänomistaja 2010 (The Finnish forest owner 2010), METLA-wp 208. METLA, Vantaa. In Finnish.

Jullien, B. and B. Salanien. 2000. Estimating preferences under risk: the case of racetrack bettors. Journal of Political Economy 108:503-530.

Löyland, K., V. Kringstad, and H. Ö. 1995. Determinants of forest activities - a study of private non-industrial forestry in Norway. Journal of Forest Economics 1(2): 219-237.

O'Neill, B. and M. Desai. 2005. Accuracy of past projections of US energy consumption. Energy Policy 33( 8):979-993.

Pesaran, M.H. and Skouras, S. 2002. Decision-Based methods for forecast evaluation in A Companion to Economic Forecasting (eds. Clements, M.P. \& Hendry, D.F.), 241-267. Blackwell, London.

Pesaran, M.H. and Weale, M. 2006. Survey expectations in The Handbook of Economic Forecasting (eds. Elliott, G., Granger. C.W.J. \& Timmermann, A.), 715-776. North-Holland, Amsterdam.

Raj, D. 1968. Sampling Theory. McGraw-Hill, London.

Royer, J. 1987. Determinants of reforestation behavior among southern landowners. For.Sci. 33(3), 654-667.

Sakva, D. 2005. Evaluation of Errors in National Energy Forecasts. Ph.D. thesis, Rochester Institute of Technology, NY. 2005.

Sung, M. and J.E.V. Johnson. 2008. Semi-Strong form information efficiency in horse race betting markets in Handbook of Sports and Lottery Markets, Hausch, D.B. and W.T. Ziemba (eds.) 275-306. Elsevier.

Zhang, D. and P. Flick. 1977. Sticks, carrots and reforestation investment. Land Economics 77(3): 443-456.

Washburn, C.L. and C.S. Binkley 1990. Informational efficiency of markets for stumpage. Am.J.Agr.Econ 72(2):394-405. 
Table1. Population proportion estimates $(n=5642, N=308352)$.

\begin{tabular}{cccccc}
\hline Category & Proportion & Std. Error & Lower 95\% Cl & Upper 95\% Cl & CV \% \\
\hline 0 & 0.2125 & 0.0054 & 0.2021 & 0.2232 & 2.54 \\
1 & 0.1804 & 0.0051 & 0.1707 & 0.1906 & 2.81 \\
2 & 0.2494 & 0.0057 & 0.2384 & 0.2607 & 2.28 \\
3 & 0.2774 & 0.0059 & 0.2659 & 0.2891 & 2.12 \\
4 & 0.0607 & 0.0031 & 0.0549 & 0.0673 & 5.18 \\
5 & 0.0195 & 0.0018 & 0.0162 & 0.0234 & 9.35 \\
\hline
\end{tabular}


Table 2. Information variables.

\begin{tabular}{ll}
\hline Variable name & Contents \\
\hline INFO & $\begin{array}{l}\text { importance level of forestry information sources (a sum of personal valuation of } 10 \text { different sources: TV, internet, daily newspapers, } \\
\text { forestry journals, forestry books, forest plan, home delivered forestry flyers and hand-outs, meetings, forestry courses, and personal } \\
\text { information by forestry professionals, valued as } 0=\text { not important, } 1=\text { some importance, and } 2=\text { important) } \\
\text { activity level of reading forestry journals (personal level sum of activity over } 12 \text { different journals: } 0=\text { not reading, } 1=\text { reads, but is not } \\
\text { subscriber, and } 2=\text { subscriber) } \\
\text { number of contacts for information with forestry professionals during } 2004-2008\end{array}$ \\
CONTACT_A & num
\end{tabular}


Table 3. Summary statistics of the information variables.

\begin{tabular}{cccc} 
& JOUR & INFO & CONTACT_A \\
\hline Mean & 3.861 & 8.908 & 9.357 \\
Median & 3.000 & 9.000 & 5.000 \\
Maximum & 12.00 & 20.00 & 247.0 \\
Minimum & 0.000 & 1.000 & 0.000 \\
Std. Dev. & 2.489 & 3.996 & 15.31 \\
Skewness & 0.484 & $3 \mathrm{E}-04$ & 6.060 \\
Kurtosis & 2.452 & 2.233 & 59.49 \\
Observations & 5817 & 5870 & 5940 \\
\hline
\end{tabular}


Table 4. Average marginal probability effects (AMPE) of information variables ( $\mathrm{z}$-values in parenthesis).

\begin{tabular}{|c|c|c|c|c|}
\hline \multirow{3}{*}{$\begin{array}{c}\text { CHOSEN, } \mathbf{N}=\mathbf{5 1 6 2} \\
\text { CATEGORY = } \\
\text { INFO }\end{array}$} & \multicolumn{2}{|c|}{ MN } & \multicolumn{2}{|c|}{ OL } \\
\hline & & & & \\
\hline & -0.0102 & $(-16.04)$ & -0.0063 & $(-13.00)$ \\
\hline JOUR & -0.0332 & $(-27.50)$ & -0.0151 & $(-19.16)$ \\
\hline CONTACT_A & -0.0011 & $(-3.78)$ & -0.0001 & $(-0.85)$ \\
\hline \multicolumn{5}{|l|}{ CATEGORY $=1$} \\
\hline INFO & 0.0010 & $(1.60)$ & -0.0030 & $(-13.34)$ \\
\hline JOUR & 0.0079 & (7.55) & -0.0072 & $(-20.78)$ \\
\hline CONTACT_A & 0.0008 & (6.21) & -0.0004 & $(-0.82)$ \\
\hline \multicolumn{5}{|l|}{ CATEGORY $=2$} \\
\hline INFO & 0.0029 & (3.92) & 0.0026 & (5.13) \\
\hline JOUR & 0.0107 & (9.56) & 0.0068 & (5.30) \\
\hline CONTACT_A & 0.0005 & $(0.30)$ & 0.0000 & $(0.90)$ \\
\hline \multicolumn{5}{|l|}{ CATEGORY $=3$} \\
\hline INFO & 0.0060 & (7.91) & 0.0061 & (13.22) \\
\hline JOUR & 0.0116 & (9.97) & 0.0146 & (20.28) \\
\hline CONTACT A & -0.0003 & $(-1.37)$ & 0.0000 & $(0.84)$ \\
\hline \multicolumn{5}{|l|}{ CATEGORY $=4$} \\
\hline INFO & 0.0004 & $(1.07)$ & 0.0022 & (12.94) \\
\hline JOUR & 0.0016 & (2.63) & 0.0052 & (18.82) \\
\hline CONTACT_A & 0.0003 & $(4.40)$ & 0.0000 & $(0.91)$ \\
\hline \multicolumn{5}{|l|}{ CATEGORY $=5$} \\
\hline INFO & -0.0002 & $(-0.79)$ & 0.0007 & (11.72) \\
\hline JOUR & 0.0014 & (3.78) & 0.0018 & (15.30) \\
\hline CONTACT_A & 0.0001 & (2.79) & 0.0000 & $(0.85)$ \\
\hline
\end{tabular}


Table 5. Average marginal probability effects (AMPE) of MN model parameter estimates (continuous variables and effect values with $|z|$-value above 2 are printed with bold font).

\begin{tabular}{|c|c|c|c|c|c|c|}
\hline VARIABLES & Category $=0$ & Category=1 & Category=2 & Category=3 & Category=4 & Category $=5$ \\
\hline \multicolumn{7}{|l|}{$\begin{array}{l}\text { Information } \\
\text { variables }\end{array}$} \\
\hline INFO & -0.0054 & -0.0001 & 0.0005 & 0.0043 & 0.0003 & 0.0002 \\
\hline JOUR & -0.0185 & 0.0032 & 0.0066 & 0.0079 & -0.0000 & 0.0008 \\
\hline CONTACT_A & 0.0004 & 0.0001 & -0.0009 & -0.0000 & 0.0004 & 0.0007 \\
\hline \multicolumn{7}{|l|}{$\begin{array}{l}\text { Activity } \\
\text { variables }\end{array}$} \\
\hline$\overline{D E L I V \_m}$ & -0.0259 & 0.0363 & -0.0063 & -0.0024 & -0.0082 & 0.0066 \\
\hline OCC_st3 & -0.0355 & 0.0163 & -0.0327 & 0.0586 & -0.0074 & 0.0008 \\
\hline FOREEST_job2 & -0.0765 & 0.0409 & -0.0203 & 0.0906 & -0.0266 & -0.0081 \\
\hline PERM_h & 0.0122 & 0.0294 & -0.0336 & -0.0175 & 0.0172 & -0.0076 \\
\hline RESIDENT p2 & 0.0355 & -0.0317 & -0.0054 & -0.0003 & 0.0174 & -0.0154 \\
\hline HOLDING_édec & 0.0335 & -0.0016 & 0.0043 & -0.0155 & -0.0131 & -0.0076 \\
\hline TEMP_h & 0.0134 & 0.0263 & -0.0141 & -0.0100 & -0.0127 & -0.0028 \\
\hline FOREST_plan & -0.0114 & -0.0166 & 0.0152 & 0.0142 & 0.0070 & -0.0085 \\
\hline SELLINGS & -0.0310 & 0.0165 & 0.0483 & 0.0008 & -0.0228 & -0.0118 \\
\hline SELLINGS_exp1 & -0.0913 & 0.0096 & 0.0484 & 0.0305 & -0.0022 & 0.0048 \\
\hline SELLINGS_exp2 & -0.1088 & -0.0104 & 0.0278 & 0.0563 & 0.0160 & 0.0191 \\
\hline SELLINGS_exp3 & -0.1062 & 0.0644 & 0.0227 & 0.0057 & 0.0015 & 0.0118 \\
\hline \multicolumn{7}{|l|}{$\begin{array}{l}\text { Background } \\
\text { variables }\end{array}$} \\
\hline FOREST_dis8 & -0.0002 & -0.0025 & -0.0007 & -0.0059 & 0.0030 & 0.0011 \\
\hline FOREST_dis 9 & -0.0050 & -0.0006 & 0.0047 & 0.0021 & 0.0002 & -0.0014 \\
\hline HOLDING_size & 0.0095 & 0.0019 & 0.0021 & -0.0038 & -0.0277 & 0.0000 \\
\hline LANGAUGE & 0.0797 & 0.0303 & -0.0460 & -0.0400 & -0.0240 & -0.0000 \\
\hline GENDER & 0.1063 & -0.0427 & -0.0819 & 0.0262 & 0.0007 & -0.0086 \\
\hline EDU_1 & -0.0374 & 0.0025 & -0.0051 & 0.0298 & 0.0053 & 0.0048 \\
\hline EDU_2 & -0.0742 & 0.0074 & 0.0320 & 0.0147 & 0.0156 & 0.0044 \\
\hline $\mathrm{OCC}^{-}$st 5 & -0.0037 & -0.0175 & 0.0482 & -0.0156 & -0.0325 & 0.0213 \\
\hline FORE $S T$ Tobl & 0.0128 & 0.0086 & -0.0337 & 0.0380 & -0.0097 & -0.0159 \\
\hline non_FOREST_se & 0.0284 & -0.0255 & 0.0028 & 0.0094 & -0.0075 & -0.0075 \\
\hline NON_h & -0.0013 & 0.0527 & -0.0279 & -0.0146 & -0.0083 & -0.0052 \\
\hline non_CONTACT & 0.0054 & 0.0121 & 0.0008 & 0.0021 & -0.0069 & -0.0135 \\
\hline non_ACTIVITY & 0.0258 & 0.0062 & -0.0018 & -0.0079 & -0.0233 & 0.0011 \\
\hline
\end{tabular}


Table 6. Average marginal probability effects (AMPE) of OL model parameter estimates (continuous variables and effect values with $|z|$-value above 2 are printed with bold font).

\begin{tabular}{|c|c|c|c|c|c|c|}
\hline VARIABLES & Category $=0$ & Category=1 & Category=2 & Category $=3$ & Category $=4$ & Category $=5$ \\
\hline \multicolumn{7}{|l|}{$\begin{array}{l}\text { Information } \\
\text { variables }\end{array}$} \\
\hline INFO & -0.0044 & -0.0023 & 0.0025 & 0.0045 & 0.0015 & 0.0005 \\
\hline JOUR & -0.0082 & -0.0043 & 0.0004 & 0.0083 & 0.0028 & 0.0009 \\
\hline CONTACT_A & -0.0000 & -0.0000 & 0.0000 & 0.0000 & 0.0000 & 0.0000 \\
\hline \multicolumn{7}{|l|}{$\begin{array}{l}\text { Activity } \\
\text { variables }\end{array}$} \\
\hline DELIV_m & 0.0027 & 0.0014 & -0.0013 & -0.0027 & -0.0093 & -0.0003 \\
\hline OCC_sț & -0.0247 & -0.0130 & 0.0012 & 0.0252 & 0.0085 & 0.0029 \\
\hline FORE $S T$ TOb2 & -0.0071 & -0.0037 & 0.0003 & 0.0073 & 0.0024 & 0.0008 \\
\hline PERM_h & 0.0136 & 0.0071 & -0.0006 & -0.0138 & -0.0046 & -0.0015 \\
\hline RESID̄ENT_p2 & 0.0094 & 0.0049 & -0.0004 & -0.0096 & -0.0032 & -0.0011 \\
\hline HOLDING $\overline{\mathrm{dec}}$ & 0.0251 & 0.0132 & -0.0012 & -0.0255 & -0.0086 & -0.0029 \\
\hline TEMP_h ${ }^{-}$ & 0.0226 & 0.0118 & -0.0011 & -0.0229 & -0.0077 & -0.0026 \\
\hline FORESTT_plan & -0.0133 & -0.0070 & 0.0065 & 0.0135 & 0.0046 & 0.0015 \\
\hline SELLINGS & 0.0000 & 0.0000 & -0.0000 & -0.0004 & -0.0001 & 0.0000 \\
\hline SELLINGS_exp1 & -0.0471 & -0.0247 & 0.0023 & 0.0479 & 0.0162 & 0.0054 \\
\hline SELLINGS_exp2 & -0.0639 & -0.0336 & 0.0331 & 0.0651 & 0.0220 & 0.0074 \\
\hline SELLINGS_exp3 & -0.0251 & -0.0132 & 0.0012 & 0.0255 & 0.0086 & 0.0029 \\
\hline $\begin{array}{l}\text { VALUE_estim } \\
\text { Background } \\
\text { variables }\end{array}$ & -0.0067 & -0.0035 & 0.0003 & 0.0069 & 0.0023 & 0.0009 \\
\hline FOREST_dis 8 & -0.0034 & -0.0017 & 0.0002 & 0.0034 & 0.0011 & 0.0004 \\
\hline FOREST dis 9 & -0.0024 & -0.0013 & 0.0001 & 0.0024 & 0.0008 & 0.0003 \\
\hline HOLDING size & 0.0158 & 0.0083 & -0.0001 & -0.0016 & -0.0054 & -0.0002 \\
\hline LANGAUGE & 0.0737 & 0.0387 & -0.0036 & -0.0750 & -0.0253 & -0.0085 \\
\hline GENDER & 0.0536 & 0.0283 & -0.0026 & -0.0545 & -0.0184 & -0.0062 \\
\hline EDU 1 & -0.0281 & -0.0148 & 0.0014 & 0.0286 & 0.0097 & 0.0032 \\
\hline $\mathrm{EDU}^{-} 2$ & -0.0386 & -0.0203 & 0.0019 & 0.0393 & 0.0133 & 0.0045 \\
\hline occst 5 & -0.0090 & -0.0047 & 0.0004 & 0.0091 & 0.0031 & 0.0010 \\
\hline FORE $\overline{E T}$ job1 & 0.0133 & 0.0069 & -0.0006 & -0.0135 & -0.0046 & -0.0015 \\
\hline non_FOREST_se & 0.0098 & 0.0052 & -0.0005 & -0.0099 & -0.0034 & -0.0011 \\
\hline NON ${ }^{-} \mathrm{h}$ & 0.0215 & 0.0113 & -0.0010 & -0.0218 & -0.0074 & -0.0025 \\
\hline non CONTACT & 0.0230 & 0.0121 & -0.0011 & -0.0233 & -0.0078 & -0.0026 \\
\hline non ACTIVITY & 0.0214 & 0.0113 & -0.0010 & -0.0217 & -0.0074 & -0.0024 \\
\hline
\end{tabular}


Table 7. Observed timber price changes $\Delta \ln p_{k}$ at the end of 2009 and the corresponding CHOSEN variable value.

\begin{tabular}{ccc}
\hline REGION & PRICE CHANGE & CHOSEN \\
\hline Whole country & -0.143 & 1 \\
Region 1 & -0.145 & 1 \\
Region 2 & -0.093 & 2 \\
Region 3 & -0.067 & 2 \\
Region 4 & -0.068 & 2 \\
Region 5 & -0.117 & 1 \\
Region 6 & -0.220 & 1 \\
\hline
\end{tabular}




\section{Appendix 1}

\section{Table A1-1 Activity variables.}

\begin{tabular}{|c|c|}
\hline Variable name & Contents \\
\hline DELIV_m & $\begin{array}{l}1 / 0 \text { dummy variable for establishing the ownership of the forest property by market purchase (as opposed to acquiring the property by } \\
\text { a purchase from relatives, by donation or by inheritance) }\end{array}$ \\
\hline OCC_st3 & $1 / 0$ dummy variable for self-employment in forestry as occupation status \\
\hline FORĒST_job2 & $1 / 0$ dummy variable for wage earner in forest sector as job status \\
\hline FOREST_job3 & $1 / 0$ dummy variable for entrepreneur in forest sector as job status \\
\hline PERM_h & $1 / 0$ dummy variable for regular housing on the site of forest property \\
\hline RESIDENT_p1 & $1 / 0$ dummy variable for permanent residence on the site of the forest property \\
\hline RESIDENT_p2 & $1 / 0$ dummy variable for residence in the municipality of the forest property \\
\hline HOLDING_change & $\begin{array}{l}1 / 0 \text { dummy variable for change of area size of owned forest property during } 2003-2008,(1=\text { changes have happened, } 0=\text { no changes } \\
\text { have happened) }\end{array}$ \\
\hline HOLDING_dec & 1/0 dummy variable for plans of buying, selling, or ceding of forest land in years $2009-2013$ \\
\hline DAYS_on_HOLDING & the number of days spent on the site in 2008 \\
\hline FORES̄T_plan & $1 / 0$ dummy variable for having a forest plan \\
\hline ACTIVITY_A & number of participation in forestry related occasions and meetings during the years $2004-2008$ \\
\hline DAYS_A - & $\begin{array}{l}\text { forest owner's estimate of the number of days spent on forestry activities such as self-education, receiving information, meetings, } \\
\text { planning, and monitoring }\end{array}$ \\
\hline SELLINGS & $1 / 0$ dummy variable for timber sales during $2003-2008$ \\
\hline SELLINGS_exp1 & 1/0 dummy variable for plans to sell more timber in $2009-2013$ as compared to the years $2003-2008$ \\
\hline SELLINGS_exp2 & $1 / 0$ dummy variable for plans to sell equal amount of timber in $2009-2013$ as compared to $2003-2008$ \\
\hline SELLINGS_exp3 & $1 / 0$ dummy variable for plans to sell less timber in $2009-2013$ as compared to $2003-2008$ \\
\hline SELLINGS_exp4 & 1/0 dummy variable for plans of not selling timber in $2009-2013$ \\
\hline SELLINGS_exp5 & 1/0 dummy variable for not knowing whether timber will be sold $2009-2013$ \\
\hline VALUE_estim & $\begin{array}{l}\text { forest owner's estimate of the price for which he/she is ready to sell his/her forest property: } 0=\text { not selling or not able to say, } 1=\text { at } \\
\text { market price, } 2=\text { at } 1.2 \times \text { market price, } 3=\text { at } 1.5 \times \text { market price, } 4=\text { at } 2 \times \text { market price, } 5=\text { at } 3 \times \text { market price, } 6=\text { over } 3 \times \text { market } \\
\text { price. }\end{array}$ \\
\hline
\end{tabular}


Table A1-2 Background and non-activity variables.

\begin{tabular}{|c|c|}
\hline Variable name & Contents \\
\hline FOREST_dis_i & $1 / 0$ dummy variable for the Forest Center district $(i=1,2, \ldots, 13)$ where the forest property is located \\
\hline HOLDING_size & the size of the forest property (in $0.01 x$ hectares) \\
\hline OWNER_p & $1 / 0$ dummy variable for private (family) ownership of property \\
\hline OWNER_co & $1 / 0$ dummy variable for corporate ownership of property \\
\hline OWNER_est & $1 / 0$ dummy variable for estate ownership of property \\
\hline INCOME & forest owner's earnings income \\
\hline CAPITAL_inc & forest capital income \\
\hline FOREST_e_area & ownership of forest area owned by the forest owner in other municipalities (in $0.01 x$ hectares) \\
\hline DELIV_her & $1 / 0$ dummy variable for having established the ownership of the forest by inheritage \\
\hline DELIV_rel & $1 / 0$ dummy variable for having established the ownership of the forest by purchasing from relatives \\
\hline DELIV_year & the year of establishing the ownership \\
\hline LANGÜAGE & $1 / 0$ dummy variable for forest owner's native language $(1=$ Swedish, $0=$ Finnish $)$ \\
\hline GENDER & $1 / 0$ dummy variable for forest owner's the gender $(1=$ female, $0=$ male $)$ \\
\hline EDU_0 & $1 / 0$ dummy variable for non-professional education \\
\hline EDU_1 & $1 / 0$ dummy variable for lower level professional education \\
\hline EDU_2 & $1 / 0$ dummy variable for higher level professional education \\
\hline EDU_3 & $1 / 0$ dummy variable for academic professional education \\
\hline $\mathrm{AG} \overline{\mathrm{E}}$ & age of the forest owner \\
\hline OCC_st1 & $1 / 0$ dummy variable for wage earner as the occupation status \\
\hline $\mathrm{OCC}_{-}^{-} \mathrm{st} 2$ & $1 / 0$ dummy variable for self-employment in agriculture as the occupation status \\
\hline $\mathrm{OCC}_{-}^{-} \mathrm{st} 4$ & $1 / 0$ dummy variable for self-employment outside agriculture or forestry as the occupation status \\
\hline OCC_st5 & $1 / 0$ dummy variable for retirement as the occupation status \\
\hline FOREST job1 & $1 / 0$ dummy variable for forest owner not being employed by forest industry \\
\hline TEMP_h & $1 / 0$ dummy variable for owning a leisure time house on the forest property \\
\hline NON_h & $1 / 0$ dummy variable for the forest property not having any buildings \\
\hline RESIDEN̄T_p3 & $1 / 0$ dummy variable for residence in a municipality other than where forest property is located \\
\hline RESIDENT_dis & the distance (in km's) of forest property from the location of the forest owner's residence \\
\hline RESIDENT_type 1 & $1 / 0$ dummy variable for residence in rural district \\
\hline RESIDENT_type2 & $1 / 0$ dummy variable for residence in semi-urban district \\
\hline RESIDENT_type3 & $1 / 0$ dummy variable for residence in urban district (small town) \\
\hline RESIDENT_type4 & $1 / 0$ dummy variable for residence in urban district (large town) \\
\hline non-FORESTT_se & $1 / 0$ dummy variable for not being self-employed on the forest property \\
\hline non_CONTAC̄T & $1 / 0$ dummy variable for not having contacts with forestry professionals during $2004-2008$ \\
\hline non_ACTIVITY & 1/0 dummy variable for not participating in different forestry information occasions and meetings during $2004-2008$. \\
\hline
\end{tabular}




\section{Appendix 2}

Table A2-1. Univariate statistics and missing value shares for continuous sample variables.

\begin{tabular}{cccccccc}
\hline & $\mathrm{N}$ & Mean & Std. Deviation & \multicolumn{2}{c}{ Missing } & \multicolumn{3}{c}{$\begin{array}{c}\text { No. of Extremes } \\
\text { Low } \\
\text { High }\end{array}$} \\
\hline CHOSEN & 5642 & 1.85 & 1.306 & 676 & 10.7 & 0 & 110 \\
INFO & 5870 & 8.91 & 3.996 & 448 & 7.1 & 0 & 113 \\
JOUR & 5817 & 3.86 & 2.489 & 501 & 7.9 & 0 & 253 \\
CONTACT_A & 5940 & 9.36 & 15.314 & 378 & 6.0 & 0 & 184 \\
DAYS_on_HOLDING & 5511 & 172.51 & 164.949 & 807 & 12.8 & 0 & 0 \\
ACTIVITY_A & 5797 & 1.70 & 5.918 & 521 & 8.2 & 0 & 107 \\
DAYS_A & 5589 & 5.26 & 9.389 & 729 & 11.5 & 0 & 166 \\
VALUE_estim & 5849 & 0.76 & 1.679 & 469 & 7.4 & 0 & 418 \\
HOLDING_size & 6318 & 0.359 & 0.527 & 0 & 0.0 & 0 & 162 \\
INCOME & 5494 & 32.24 & 51.767 & 824 & 13.0 & 0 & 45 \\
CAPITAL_inc & 6318 & 5.68 & 16.895 & 0 & 0.0 & 0 & 222 \\
DELIV_year & 5686 & 1987.23 & 15.133 & 632 & 10.0 & 193 & 0 \\
AGE & 5685 & 60.63 & 12.722 & 633 & 10.0 & 190 & 55 \\
RESIDENT_dis & 6318 & 75.21 & 215.373 & 0 & 0.00 & 0 & 183 \\
\hline & a. Number of cases outside the range (Mean - 2*SD, Mean + 2*SD). &
\end{tabular}

Table A2-2. The effects of missing values of the dependent variable CHOSEN on the continuous variables.

\begin{tabular}{|c|c|c|c|c|c|c|c|}
\hline Variable & t-value*) & df & p-value & \#Present & \#Missing & $\begin{array}{c}\text { Mean } \\
\text { (present) }\end{array}$ & $\begin{array}{c}\text { Mean } \\
\text { (Missing) }\end{array}$ \\
\hline INFO & 12.9 & 490 & 0.00 & 5449 & 421 & 9.09 & 6.56 \\
\hline JOUR & 13.2 & 493.9 & 0.00 & 5413 & 404 & 3.96 & 2.53 \\
\hline CONTACT_A & 8.8 & 696.2 & 0.00 & 5483 & 457 & 9.68 & 5.43 \\
\hline $\begin{array}{l}\text { DAYS_on } \\
\text { HOLDING }\end{array}$ & -2.6 & 497.5 & 0.001 & 5083 & 428 & 170.77 & 193.15 \\
\hline ACTIVITY_A & 1.8 & 543.6 & 0.07 & 5335 & 462 & 1.74 & 1.21 \\
\hline DAYS_A & 7.5 & 412.3 & 0.00 & 5276 & 313 & 5.41 & 2.67 \\
\hline $\begin{array}{l}\text { VALUE_- } \\
\text { estim }\end{array}$ & 6.6 & 539.4 & 0.00 & 5436 & 413 & 0.79 & 0.36 \\
\hline $\begin{array}{c}\text { HOLDING_ }_{\text {size }}\end{array}$ & 5.5 & 1153 & 0.00 & 5642 & 676 & 36.86 & 28.66 \\
\hline INCOME & 6.6 & 1288.6 & 0.00 & 4889 & 605 & 33.23 & 24.27 \\
\hline CAPITAL_inc & 5.8 & 1108.4 & 0.00 & 5642 & 676 & 5.98 & 3.12 \\
\hline DELIV-year & 6.0 & 584.7 & 0.00 & 5175 & 511 & 1987.66 & 1982.85 \\
\hline AGE & -14.3 & 636.5 & 0.00 & 5155 & 530 & 59.85 & 68.20 \\
\hline RESID._dis & 2.0 & 815.5 & 0.03 & 5642 & 676 & 77.22 & 58.49 \\
\hline
\end{tabular}

*) t-test for group variance equality between present and missing group values determined by variable CHOSEN for specific indicator variable. 
Table A2-3. Missing value shares of the variable CHOSEN (non-missing 5642, missing 676) for selected $0 / 1$-variables.

\begin{tabular}{|c|c|c|c|}
\hline Variable & & 0 & 1 \\
\hline \multirow[t]{3}{*}{ FOREST_job2 } & PRESENT count & 5306 & 336 \\
\hline & percent & 89.0 & 94.4 \\
\hline & MISSING percent & 11.0 & 5.6 \\
\hline \multirow[t]{3}{*}{ FOREST_plan } & PRESENT count & 2254 & 3358 \\
\hline & percent & 84.3 & 92.9 \\
\hline & MISSING percent & 15.7 & 7.1 \\
\hline \multirow[t]{3}{*}{ SELLINGS } & PRESENT count & 1751 & 3139 \\
\hline & percent & 90.2 & 97.4 \\
\hline & MISSING percent & 9.8 & 2.6 \\
\hline \multirow[t]{3}{*}{ SELLING_exp1 } & PRESENT count & 5021 & 621 \\
\hline & percent & 88.3 & 98.4 \\
\hline & MISSING percent & 11.7 & 1.6 \\
\hline \multirow[t]{3}{*}{ SELLING_exp2 } & PRESENT count & 4920 & 712 \\
\hline & percent & 88.2 & 98.1 \\
\hline & MISSING percent & 11.8 & 1.9 \\
\hline \multirow[t]{3}{*}{ SELLING_exp3 } & PRESENT count & 4668 & 974 \\
\hline & percent & 87.6 & 98.4 \\
\hline & MISSING percent & 12.4 & 1.6 \\
\hline \multirow[t]{3}{*}{ SELLING_exp4 } & PRESENT count & 3592 & 2050 \\
\hline & percent & 87.0 & 93.6 \\
\hline & MISSING percent & 13.0 & 6.4 \\
\hline \multirow[t]{3}{*}{ DELIV_rel } & PRESENT count & 3486 & 2156 \\
\hline & percent & 87.4 & 92.6 \\
\hline & MISSING percent & 12.6 & 7.4 \\
\hline \multirow[t]{3}{*}{ LANGUAGE } & PRESENT count & 5335 & 307 \\
\hline & percent & 89.6 & 84.8 \\
\hline & MISSING percent & 10.4 & 15.2 \\
\hline \multirow[t]{3}{*}{ GENDER } & PRESENT count & 4338 & 1304 \\
\hline & percent & 91.1 & 83.9 \\
\hline & MISSING percent & 8.9 & 16.1 \\
\hline \multirow[t]{3}{*}{ EDU_2 } & PRESENT count & 4468 & 1174 \\
\hline & percent & 88.0 & 94.8 \\
\hline & MISSING percent & 12.0 & 16.1 \\
\hline \multirow[t]{3}{*}{ EDU_3 } & PRESENT count & 4966 & 676 \\
\hline & percent & 88.7 & 94.3 \\
\hline & MISSING percent & 11.3 & 5.7 \\
\hline \multirow[t]{3}{*}{ OCC_st1 } & PRESENT count & 3903 & 1739 \\
\hline & percent & 87.2 & 94.4 \\
\hline & MISSING percent & 12.8 & 5.6 \\
\hline \multirow[t]{3}{*}{ OCC_st2 } & PRESENT count & 4852 & 790 \\
\hline & percent & 88.6 & 93.9 \\
\hline & MISSING percent & 11.4 & 6.1 \\
\hline \multirow[t]{3}{*}{ OCC_st4 } & PRESENT count & 3220 & 2422 \\
\hline & percent & 91.4 & 86.7 \\
\hline & MISSING percent & 8.6 & 13.3 \\
\hline \multirow[t]{3}{*}{ FOREST_job1 } & PRESENT count & 746 & 4896 \\
\hline & percent & 80.3 & 90.9 \\
\hline & MISSING percent & 19.7 & 9.1 \\
\hline \multirow[t]{3}{*}{ non-ACTIVITY } & PRESENT count & 2796 & 2846 \\
\hline & percent & 86.7 & 92.0 \\
\hline & MISSING percent & 13.3 & 8.0 \\
\hline
\end{tabular}

